\title{
Modelled response of the volume and thickness of the Antarctic ice sheet to the advance of the grounded area
}

\author{
Fuyuki SAITO, ${ }^{1}$ Ayako ABE-OUCHI ${ }^{1,2}$ \\ ${ }^{1} J a p a n$ Agency for Marine-Earth Science and Technology, 3173-25 Showamachi, Kanazawa-ku, Yokohama City, \\ Kanagawa 236-0001, Japan \\ E-mail: saitofuyuki@jamstec.go.jp \\ ${ }^{2}$ Center for Climate System Research, University of Tokyo, 5-1-5 Kashiwanoha, Kashiwa, Chiba 277-8568, Japan
}

\begin{abstract}
Numerical experiments are performed for the Antarctic ice sheet to study the sensitivity of the ice volume to variations in the area of grounded ice and to changes in the climate during the most recent deglaciation. The effect of the variations in the grounded area is found to be the major source of changes in the ice volume, while the effect of climate change was minor. The maximum possible contribution of the ice-volume change to sea-level rise during the deglaciation is estimated to be $36 \mathrm{~m}$, which covers most values estimated in previous studies. The effect of the advance of the ice-sheet margin over those regions not connected to the major ice shelves contributes one-third of the total ice-volume change, which is comparable to the effect of the grounding of the Filchner-Ronne Ice Shelf and the contribution of the Ross and Amery Ice Shelves together.
\end{abstract}

\section{INTRODUCTION}

Global sea-level reconstructions from coral dating or other techniques show that the sea level at the Last Glacial Maximum (LGM, around $20 \mathrm{ka}$ ) was lower by about $120 \mathrm{~m}$ than the present day (e.g. Fairbanks, 1989; Bard and others, 1996; Yokoyama and others, 2001). Melting of ice sheets during the last deglaciation was a dominant influence on sea-level change, but estimates of the contribution of the Antarctic ice sheet to this change vary widely from 0.5 to $38 \mathrm{~m}$ (Mclntyre and others, 1981; Budd and Smith, 1982; Oerlemans, 1982; Nakada and Lambeck, 1988; Bentley, 1999; Ritz and others, 2001; Denton and Hughes, 2002; Huybrechts, 2002; Peltier, 2002). In addition, the contribution of the Antarctic ice sheet to a rapid and large sea-level rise by $20-25 \mathrm{~m}$ during a period of 500 years at $14 \mathrm{ka} \mathrm{BP}$, referred to as meltwater pulse $1 \mathrm{a}$ (MWP1a), has been discussed by, for example, Bassett and others $(2005,2007)$.

Conway and others (1999) show that there was migration of the grounding line position in the Ross Sea from the LGM to the present, and the grounded area has varied significantly during the deglaciation period. An icesheet model is therefore required to simulate ice-sheet floating or ice-shelf grounding in order to follow the migration of the transient grounding line position. Several studies have applied combined ice-sheet/ice-shelf models to simulate the time evolution of the Antarctic ice sheet over glacial/interglacial cycles (Ritz and others, 2001; Huybrechts and others, 2004; Philippon and others, 2006; Pollard and DeConto, 2009).

Philippon and others (2006) found a $17.5 \mathrm{~m}$ contribution of the Antarctic ice sheet to the change in sea level during the last glaciation using an Earth system model in which the interactions between the atmosphere, ocean, vegetation and major ice sheets are represented. However, they fail to simulate the complete deglaciation over the Weddell region to match present observations.

This may be partly explained by the work of Vieli and Payne (2005) and Schoof (2007), who found that there is still some difficulty in simulating the grounding line position and its migration in numerical ice-sheet models. Vieli and Payne
(2005) concluded from a comparison of several numerical models that there is no consensus on how the grounding line should react to changes in boundary conditions. On the other hand, Schoof (2007) showed that fixing the grounding line and using the shallow-ice approximation (Hutter, 1983) yields good estimates of the ice-sheet profile, and that prescribing the grounding line position is effectively the same as assuming a back pressure from an ice shelf.

In this study, a different approach to Ritz and others (2001) and Philippon and others (2006) is taken: the steady-state surface topography is simulated by a grounded-only (i.e. ice shelf is not included) ice-sheet model. Instead of simulating the transient variation of grounded ice area, the maximum possible influence on ice volume of prescribed and fixed areas of grounded ice is discussed. The effects of changes in ice-grounded area in the Weddell, Ross, Amery and other marginal areas are each evaluated separately. Moreover, a transient experiment forced by glacial/interglacial climate change without variation in the grounded ice area is examined. A comparison between the sensitivity of ice-sheet volume and surface elevation obtained by the steady-state grounded-area experiment and the transient experiment is presented.

\section{MODEL DESCRIPTION}

The numerical model utilized in this paper, Ice sheet model for Integrated Earth system Studies (ICIES), is described in Saito and Abe-Ouchi (2004). It is a time-dependent, three-dimensional (3-D) model including thermodynamics. The basic parts of the present model are the same as for other 3-D models with thermomechanical coupling used in previous studies (e.g. Ritz and others, 2001; Abe-Ouchi and others, 2007). The model computes the evolution of the ice thickness, bedrock elevation and ice temperature under a prescribed scenario of climate forcing, in terms of the surface mass balance and temperature. The model settings such as the numerical domain, resolution, physical parameters and climate-forcing parameterizations follow Saito and Abe-Ouchi (2004). Only the essence of the 
Table 1. Summary of experiment configuration: first variable of experiment identification (grounded areas are shown in Figure 1)

\begin{tabular}{lcccccc}
\hline & \multicolumn{7}{c}{ Letter } \\
& $\mathrm{V}$ & $\mathrm{P}$ & $\mathrm{W}$ & $\mathrm{A}$ & $\mathrm{F}$ & $\mathrm{R}$ \\
\hline $\begin{array}{l}\text { Grounded area } \\
\text { Forcing }\end{array}$ & 0 & 0 & $0,1,2,3,4$ & 0,1 & 0,2 & 0,3 \\
Transient & Steady & Steady & Steady & Steady & Steady \\
\hline
\end{tabular}

ice-sheet dynamics and the framework of numerical icesheet models are repeated below.

The evolution of surface elevation is determined by the continuity equation for the local ice thickness with a prescribed surface accumulation function. The shallowice approximation is applied (Hutter, 1983) using Glen's flow law with an exponent of $n=3$ (Paterson, 1994) for the velocity computation. From this approximation, the horizontal velocity vector $\vec{v}_{H}$ can be calculated using surface elevation $h$ and bedrock topography $b$ :

$$
\vec{v}_{\mathrm{H}}=\vec{v}_{\mathrm{B}}-2\left(\rho_{\mathrm{I}} \mathrm{g}\right)^{n}\left[\int_{b}^{z} \mathrm{~d} z^{\prime} m A(T)\left(h-z^{\prime}\right)^{n}\right]|\nabla h|^{n-1} \nabla h,
$$

where $g$ is acceleration due to gravity, $\rho_{\mathrm{l}}$ is the density of ice, $\vec{v}_{\mathrm{B}}$ is basal sliding velocity and $|\nabla h|^{2}=(\partial h / \partial x)^{2}+(\partial h / \partial y)^{2}$.

The gradient in Equation (1) is in the horizontal direction only. The rate factor $A(T)$, through which the velocity and temperature fields are coupled, follows Huybrechts (1992) and Paterson (1994). The enhancement factor $m$ in Equation (1), which controls the softness of ice, implicitly reflects the effects of impurity and/or anisotropy of ice. It is used as a tuning parameter to improve the agreement between measured and modelled topography. Basal sliding is assumed to occur only when the basal ice is at the pressuremelting point, using a Weertman-type (Weertman, 1964) sliding parameterization. Bueler and Brown (2009) showed that with this kind of pressure-melting point activation of sliding, such a driving-stress-dependent sliding law will cause problems under significant grid refinement; this is potentially an important issue for future work.

The temperature distribution is calculated from the thermodynamic equation with prescribed surface temperature and geothermal heat flux at the base as boundary conditions, including the frictional heat from sliding and neglecting the basal melt rate. A prescribed temperature distribution is imposed at the surface of the ice, whereas mixed boundary conditions are applied at the bottom of the ice:

$$
\begin{cases}\left.\frac{\partial T}{\partial z}\right|_{\mathrm{b}}=-\frac{\Gamma}{k_{\mathrm{l}}} & \text { if there is no melting, } \\ T_{\mathrm{b}}=T_{\mathrm{pm}} & \text { if there is melting, }\end{cases}
$$

where $k_{\mathrm{l}}$ is the thermal conductivity of ice, $T_{\mathrm{pm}}$ is the pressure-melting point and $\Gamma$ is the geothermal heat flux. The geothermal heat flux may not be spatially non-uniform, but is taken as a constant in the present paper. Changes in the glacier bed elevation are calculated by a linear model expressing local isostatic rebound with a prescribed time constant.

Surface mass balance is calculated by the accumulation rate alone. It is expressed as the product of a reference value and a temperature-dependent factor following Huybrechts and Oerlemans (1990). Accumulation rates are reduced to
Table 2. Summary of parameter choices: second variable of experiment identification

\begin{tabular}{lrrr}
\hline & \multicolumn{3}{c}{ Letter } \\
& $\mathrm{C}$ & $\mathrm{E}$ & $\mathrm{G}$ \\
\hline Enhancement factor $m$ & 1.3 & 3 & 3 \\
Geothermal heat flux $\Gamma\left(\mathrm{mW} \mathrm{m}^{-2}\right)$ & 54.6 & 54.6 & 46 \\
\hline
\end{tabular}

$50-60 \%$ of their Holocene values with a $10 \mathrm{~K}$ decrease in surface temperature. The present reference accumulation is based on the data compiled by Huybrechts and others (2000), whose value at Dome Fuji are modified to $2.75 \mathrm{~cm} \mathrm{a}^{-1}$ according to Satow and others (1999). The data in the vicinity of Dome Fuji are smoothed after the modification. The annual surface temperature is parameterized as a function of latitude and surface elevation following Fortuin and Oerlemans (1990) and Pattyn and Decleir (1995).

The dynamics of both the ice shelves and of the grounding lines are not included in the present model. The lateral boundary is defined by floating conditions; ice that becomes afloat is cut off immediately.

The model domain spans $5600 \times 5600 \mathrm{~km}$, centred at the South Pole. The horizontal resolution is $40 \mathrm{~km}$. The bedrock topography is based on the BEDMAP database (Lythe and others, 2000). Different time-steps are used: $\Delta t=4.0$ years for the computation of the dynamic evolution and $\Delta t=$ 20.0 years for the thermodynamic evolution.

\section{EXPERIMENT DESIGN}

All the experiments in the present paper are identified by two capital letters. The first indicates treatment of the boundary condition (grounded area and climate forcing) and the second indicates the choices of uncertain parameters such as the enhancement factor and the geothermal heat flux. Two types of treatment of climate forcing are performed in this study: five steady-state experiments (identified by $\mathrm{P}, \mathrm{W}$, $\mathrm{A}, \mathrm{F}$ and $\mathrm{R}$ ) and one transient experiment (identified by $\mathrm{V}$ ). For the standard cases, an enhancement factor of 1.3 and geothermal heat flux of $54.6 \mathrm{~mW} \mathrm{~m}^{-2}$ were adopted, which is identified by the letter $C$. The letters are summarized in Tables 1 and 2 .

The steady-state simulations are performed using a prescribed grounded area. Figure 1 shows the configuration of grounded areas used in these experiments. Control experiment PC is performed with the present-day grounded area (region 0 in Fig. 1) and present-day climate, and is conducted in two steps. First, an experiment with presentday fixed ice surface elevation coupled with flow and temperature is carried out under prescribed parameters and boundary conditions without basal sliding for $200 \mathrm{ka}$. Next, a free ice-surface experiment is conducted under the same conditions, but with basal sliding for about $100 \mathrm{ka}$ to obtain a steady state.

The 'glacial maximum' experiment WC is performed for all the hatched areas in Figure 1. This grounded area is determined from various reconstructions of the LGM extents of the Antarctic ice sheet. Bentley and Anderson (1998) and Bentley (1999) presented a reconstruction of the Weddell Sea embayment during the LGM. Their 


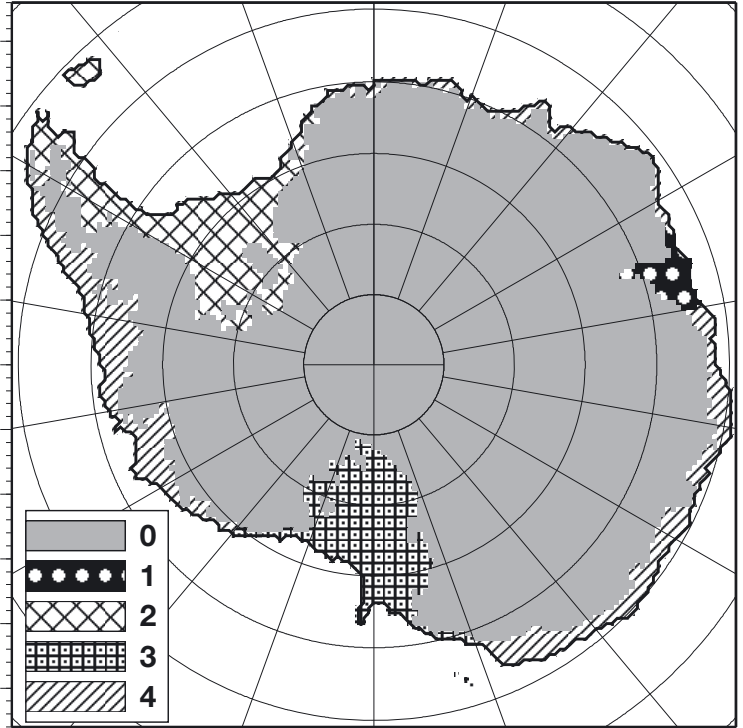

Fig. 1. The area of the grounded ice sheet used as initial conditions in the sensitivity experiments for the grounding line: (1) Amery, (2) Filchner-Ronne, (3) Ross and (4) small shelves. The grey area (0) was always grounded.

relatively confident reconstructed grounding line reached the area where bedrock elevation is lower than $-500 \mathrm{~m}$. The reconstruction of the Ross Sea embayment by McKay and others (2008) shows that the grounding line during the LGM is also in the area where the bedrock elevation is $-500 \mathrm{~m}$ or lower. Moreover, the horizontal gradient of bedrock topography is relatively gentle between -500 and $-1000 \mathrm{~m}$ and becomes steep below $-1000 \mathrm{~m}$ in most continental shelf areas (Bentley, 1999; Lythe and others, 2000).

In order to cover the whole continental shelf area, the position of the grounding line is determined by the assumption that the grounded area expands to the region of $-1000 \mathrm{~m}$ bedrock elevation in the present study. Using this threshold value, the grounded area is wider than that used by Bentley (1999) or Conway and others (1999) in some regions at the LGM.

The extent of experiment WC is assumed to correspond to the maximum extent of the Antarctic ice sheet, and is useful for sensitivity studies. The other three experiments (RC, FC and AC) are performed for the grounded area extending only over the Ross (region 0 and 3 ), the Filchner-Ronne (0 and 2 ) and the Amery ( 0 and 1$)$, respectively, in order to identify the contribution from each area. In the five steadystate experiments, accumulation and sea level are set to the present conditions to isolate the effect of the grounded area.

The transient experiment VC is the same experiment as C presented in Saito and Abe-Ouchi (2004). The model is forced by glacial/interglacial changes in the background temperature and sea level through $220 \mathrm{ka}$, while the positions of the grounding lines are prescribed and fixed as in experiment PC. The background temperature and the sea-level forcings follow the configuration of Huybrechts $(1997,2002)$. The temperature forcing is based on Vostok surface temperature change (Petit and others, 1999), and sea-level forcing is based on SPECMAP stack (Imbrie and others, 1984). The initial condition is the final state of the transient experiment beginning from experiment PC as in Ritz and others (2001). This transient experiment forced by glacial/interglacial

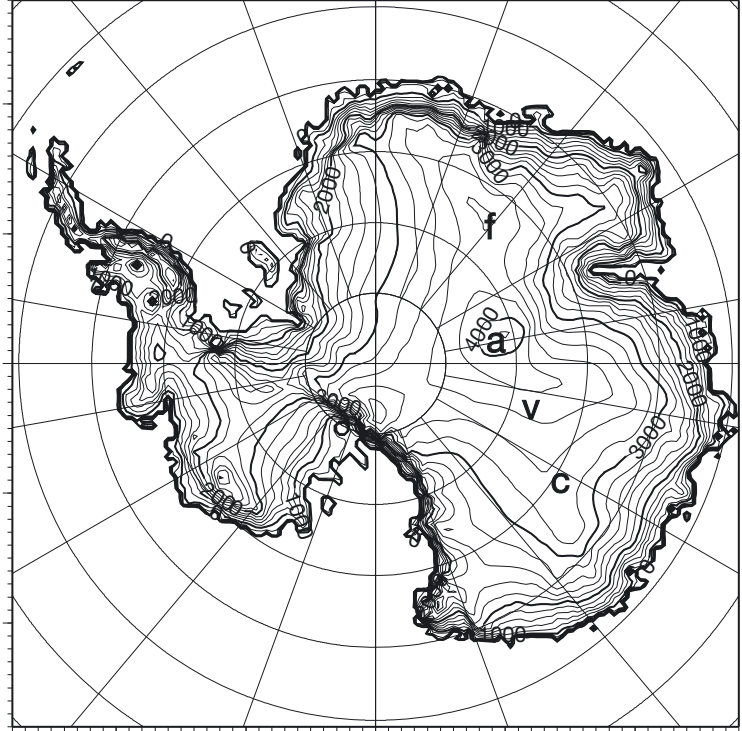

Fig. 2. Simulated present surface topography obtained by the transient experiment VC. Contour intervals are $200 \mathrm{~m}$ (thin line) and $1000 \mathrm{~m}$ (thick line). The letters $\mathrm{f}, \mathrm{a}, \mathrm{v}$ and $\mathrm{c}$ denote the positions of Dome Fuji, Dome Argus, Vostok and Dome Concordia, respectively.

climate change is performed to separate the influence on the ice-sheet volume from changes in the climate and from changes in the grounded area during the LGM.

\section{RESULTS AND DISCUSSION}

The simulated surface topography for the present obtained by the transient experiment $\mathrm{VC}$ is depicted in Figure 2. In some areas of East Antarctica, the surface elevation is overestimated (especially near the major ice shelves). This is also true over the whole of West Antarctica. The simulated total ice volume over the grounded region at present (the end of the simulation) is $31.8 \times 10^{6} \mathrm{~km}^{3}$, which is $24 \%$ larger than the present measured value of $25.7 \times 10^{6} \mathrm{~km}^{3}$ (Huybrechts and others, 2000). Philippon and others (2006) found $30.6 \times$ $10^{6} \mathrm{~km}^{3}$ at the end of their deglaciation experiment. This difference reflects the choice of uncertain parameters such as the enhancement factor or the geothermal heat flux, as well as the treatment of climate forcing.

As briefly summarized in Saito and Abe-Ouchi (2004), the enhancement factor $m=1.3$ adopted in the present paper is relatively small compared to other modelling studies (e.g. Ritz and others, 2001; Huybrechts, 2002), which may result in a larger total volume than other studies.

The time series of the total ice-sheet volume obtained by experiment VC is depicted in Figure 3. Since the experiment neglects changes in the grounded area of the ice sheet, changes in the ice volume follow the external temperature forcing. Due to the lower accumulation at lower surface temperatures, the volume in glacial periods is lower than in interglacial periods. If only changes in the external climate are taken into account, the ratio of the ice-sheet volume of the LGM to that of the present is about 0.97.

In order to investigate the sensitivity of the ice-sheet volume and its response in a changing climate to the choice of uncertain parameters, two experiments are performed with the same climate forcing but different configurations. Experiment VE applies a different enhancement factor 


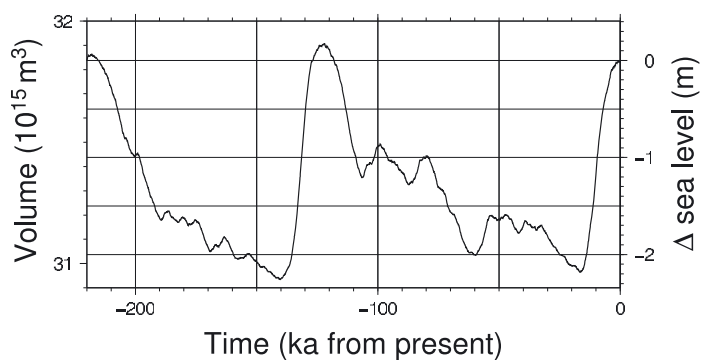

Fig. 3. Time series of the simulated total ice volume obtained by the transient experiments VC. Changes in terms of sea-level equivalent are shown on the right axis, derived from the volume change divided by $4 \times 10^{8} \mathrm{~km}^{2}$ (Allison and others, 2001).

( $m=3$ ) and the same geothermal heat flux, close to the choice of other modelling studies such as Ritz and others (2001). Experiment VG applies an enhancement factor of $m=3$ and a geothermal heat flux of $46 \mathrm{~mW} \mathrm{~m}^{-2}$.

Table 3 summarizes the results obtained by these three transient experiments. The ice volume at the end of each experiment, as well as the difference in the ice volume between the LGM and the present, are shown in terms of equivalent global sea-level change. The results show that the amplitude of changes in ice-sheet volume from the LGM to the present is not greatly affected by the choice of uncertain parameters.

To investigate the effect of changes in the ice-covered area during glacial/interglacial cycles, the results of the steady-state grounded-area experiments with four different
Table 3. Summary of simulated ice-sheet volume and its difference obtained from all experiments. Each column corresponds to three choices of the uncertain parameters. Volume and volume changes are in terms of metres sea-level equivalent volume divided by $4 \times$ $10^{8} \mathrm{~km}^{2}$ (Allison and others, 2001). The contribution by grounded area (4) is determined from the results of the other four experiments (see the text).

\begin{tabular}{|c|c|c|c|}
\hline & \multicolumn{3}{|c|}{ Parameter choice } \\
\hline & C & $\mathrm{E}$ & G \\
\hline Simulated volume at present & 80 & 73 & 76 \\
\hline $\begin{array}{l}\text { Contribution by climate effect } \\
\text { LGM-present) }\end{array}$ & -2.2 & -2.1 & -2.0 \\
\hline Grounded area contribution & & & \\
\hline $1,2,3,4)(\mathrm{W}-\mathrm{P})$ & 35.7 & 36.4 & 33.8 \\
\hline 1) $(\mathrm{A}-\mathrm{P})$ & 2.7 & 2.8 & 2.6 \\
\hline 2) $(F-P)$ & 13.7 & 13.8 & 12.8 \\
\hline 3) $(R-P)$ & 9.2 & 9.4 & 8.7 \\
\hline 4) $(\mathrm{W}-\mathrm{P}-\mathrm{A}-\mathrm{F}-\mathrm{R})$ & 10.1 & 10.4 & 9.7 \\
\hline
\end{tabular}

prescribed grounding line positions are compared. Figure 4 shows surface elevations obtained by these grounded-area experiments, which use the same choice of parameters as in the transient experiment VC. Figure 5 shows the differences between the ice thicknesses of each experiment and the steady-state control experiment PC. The results show that the most sensitive regions are concentrated in the vicinity of the ice shelves, whereas regions in the interior of the ice sheet are less affected. In some areas the change in ice thickness
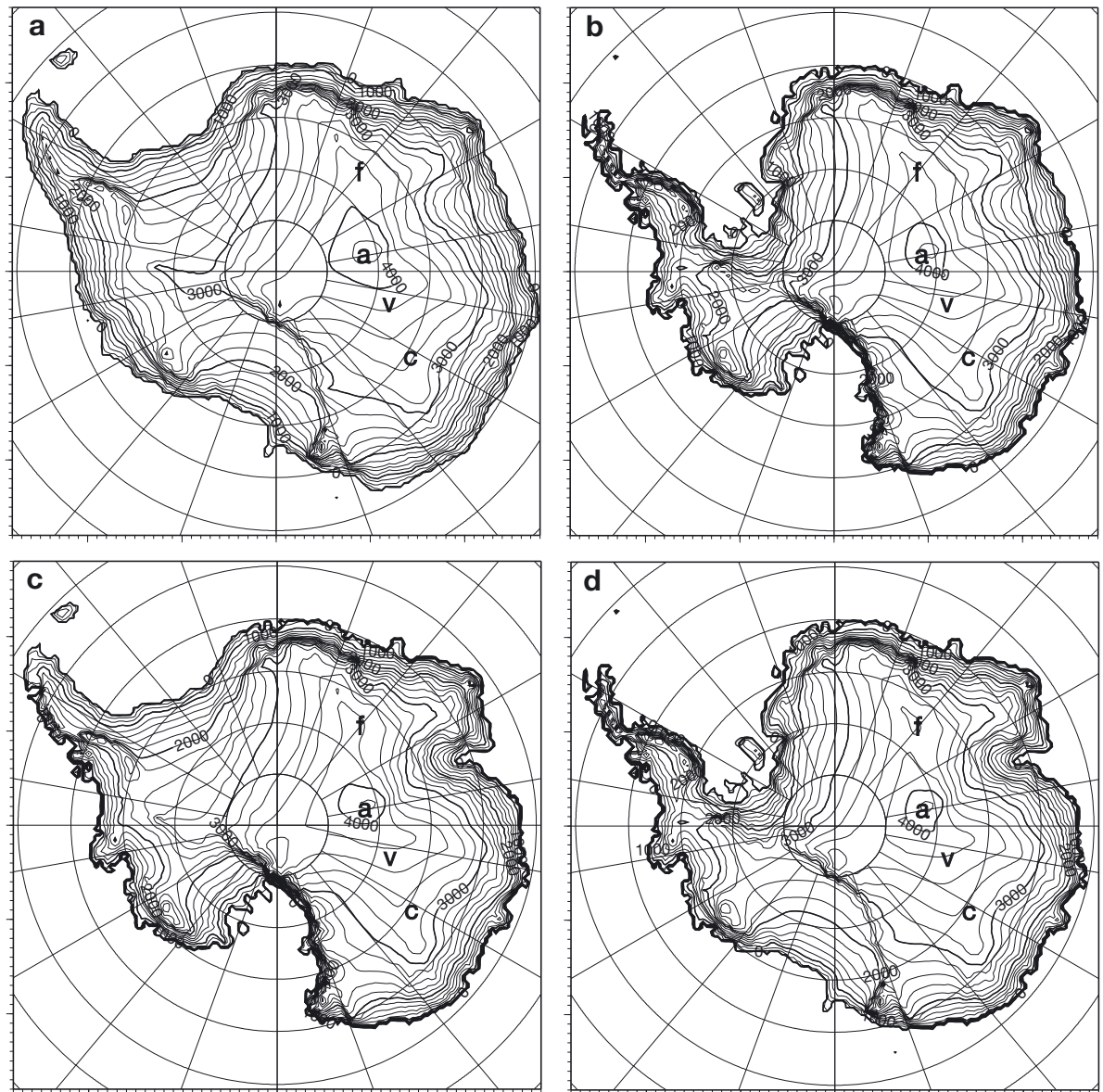

Fig. 4. Simulated surface topography obtained from grounded-area experiments: (a) WC, (b) AC, (c) FC and (d) RC. Contour intervals as for Figure 2. 

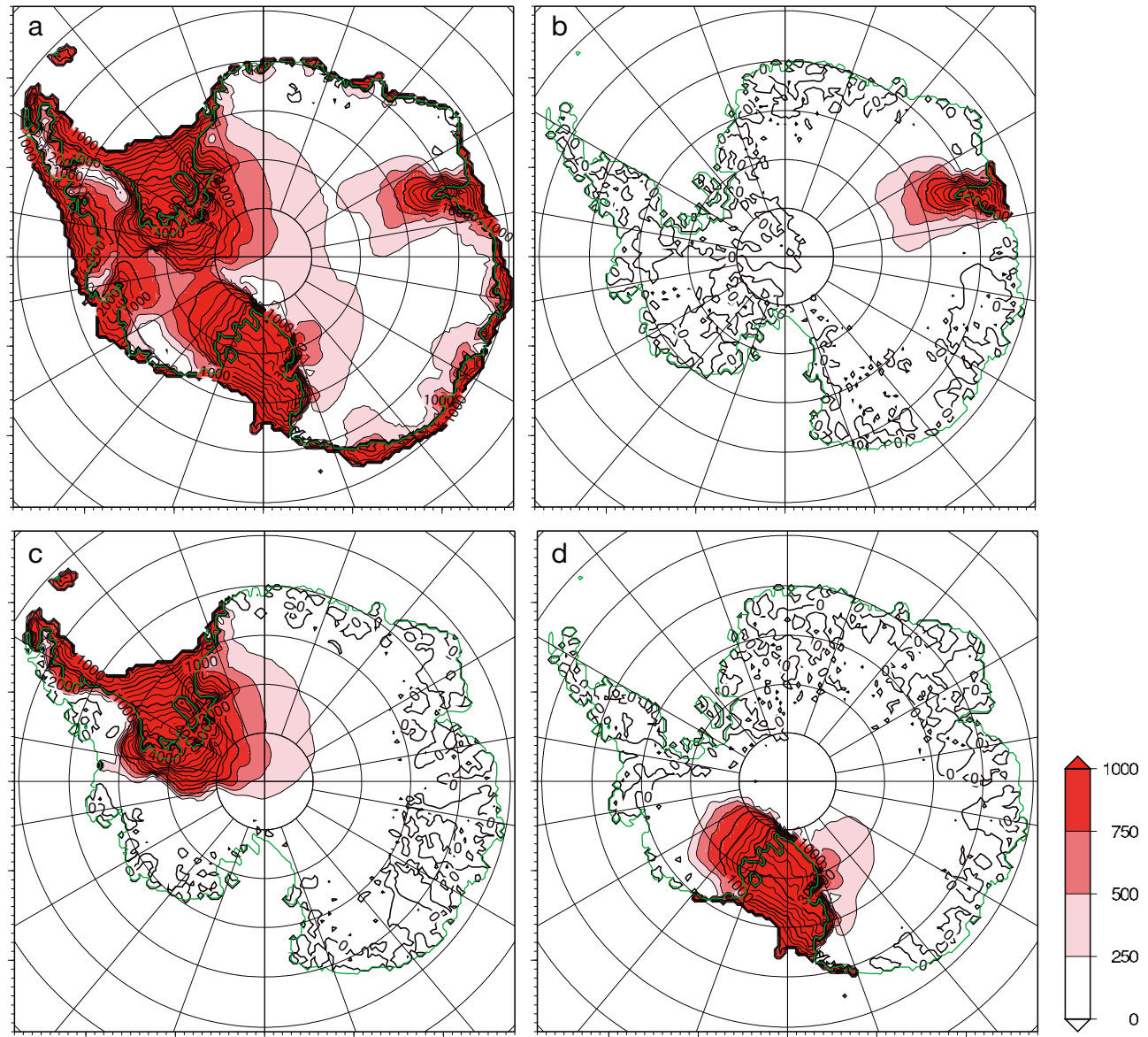

Fig. 5. Differences in simulated thickness (m) obtained by grounded-area experiments (a) WC, (b) AC, (c) FC and (d) RC relative to experiment PC. Contour interval is $250 \mathrm{~m}$. The thick green line indicates the grounded area used by experiment PC.

exceeds $1500 \mathrm{~m}$ due to changes in the grounded area, even over regions grounded at present (the dark-hatched area inside the thick lines in the figure). The effect of the FilchnerRonne Ice Shelf grounding area appears to reach further inland than that of the Ross Ice Shelf.

Observational evidence for surface elevation or thickness at the LGM is uncertain and limited (Ackert and others, 1999; Huybrechts and others, 2002). Grootes and Stuiver (1986) showed that the surface elevations were 500-600 m higher during the LGM using the Byrd core data, corresponding to the results obtained by experiment WC which are higher by $600 \mathrm{~m}$ compared to experiment PC. Since smaller accumulation due to lower temperature at the LGM leads to lower elevations than at present, the advance of the grounding line position is the crucial factor in explaining the difference in the elevation at Byrd.

The surface elevation near the ice divide is not significantly affected by the advance in the grounding line position. Figure 6 shows the difference in surface elevation from the steady-state control experiment at four sites in East Antarctica: Dome Fuji, Dome Argus, Vostok and Dome Concordia. The amplitude of the transient experiment between the LGM and the present is also shown. In these experiments, the position of Dome Concordia never becomes a dome in the model results.

The result shows that the response of surface elevation to climate change is similar among the four sites. The changes in the grounded areas have clear regionality due to the location and distance to the major ice shelves. The elevation of Dome Fuji is less sensitive to the grounding condition compared to the other sites, and is at most $50 \mathrm{~m}$. The effect from the Amery side is largest, while that on the Ross side is negligible since there are flowlines from Dome Fuji to both the Amery and Weddell regions but not to the Ross region. On the other hand, Vostok has a high sensitivity (about $130 \mathrm{~m}$ ); the effect from the Ross side is largest while that from both the Amery and Weddell regions is negligible.

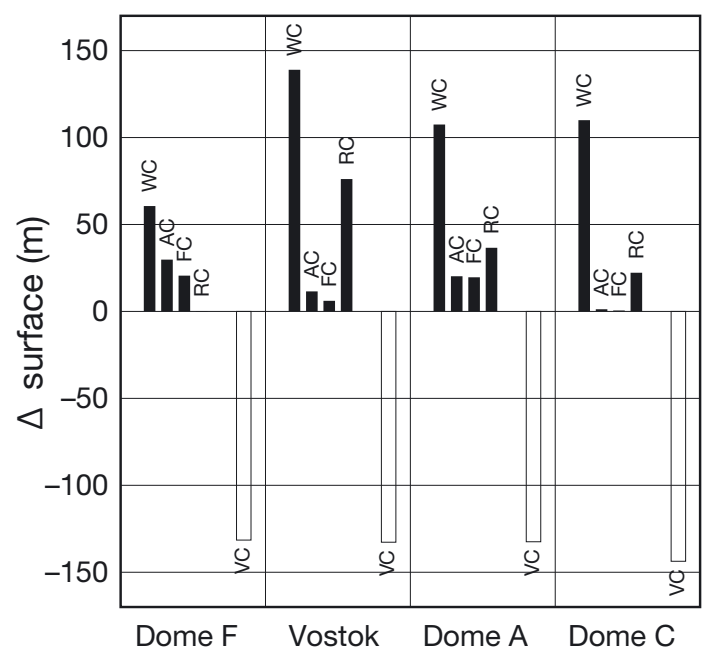

Fig. 6. Difference in simulated surface elevation at several sites for experiments $\mathrm{WC}, \mathrm{AC}, \mathrm{FC}$ and $\mathrm{RC}$ relative to experiment PC. The amplitude simulated during glacial cycles is shown for experiment VC. 
Table 3 summarizes the results obtained from the grounded-area experiments. The contribution of grounded area (4) in Figure 1 is determined from the other four results, and is assumed to be the difference between the contribution of the grounded area $(1,2,3,4)$ and the sum of those of (1), (2) and (3) separately. The advance of the grounding line over the whole periphery contributes more than $35 \mathrm{~m}$ in terms of sea-level change equivalent. The Filchner-Ronne Ice Shelf grounding area affects ice volume change the most, contributing to around one-third of the total change. The combined effects of the other two ice shelves contribute to another third of the total change. The remaining proportion of the change is due to the advance of the grounding line over the other regions not connected to the three major ice shelves (region 4 in Fig. 1).

The steady-state and transient experiments were carried out with different choices of uncertain parameters. The choices are summarized in Table 3 and are identified by $E$ and $G$, which are the same configuration as in the experiments presented and discussed in Saito and Abe-Ouchi (2004). The differences between the simulated steady-state ice volumes and the corresponding present-day steady-state experiments (PC, PE or PG) are shown in terms of equivalent global sea-level change. The result shows that the amplitude of changes in ice-sheet volume due to changes in grounded area is far greater than the effect of parameter uncertainty. The range of the simulated differences in ice volumes is within $1 \mathrm{~m}$ (except for the full glacial maximum cases in experiment WC).

Philippon and others (2006) present a sensitivity experiment (RONNY), from which the effect of grounding line retreat over the Filchner-Ronne region on changes in the ice volume from the LGM to the present can be deduced. This experiment corresponds more or less to experiment FC in the present paper. Using the same conversion from icesheet volume to equivalent global sea-level rise, the effect of grounding line retreat was $7.5 \mathrm{~m}$ in their study $(\sim 60 \%$ of the result found in the present study). The model used in Philippon and others (2006) includes ice-shelf dynamics, and the experiment is regarded as a full transient run, including transient change of grounded area during glacial/interglacial cycles. However, the Filchner-Ronne Ice Shelf was not completely deglaciated at the end of their simulation. If sufficient deglaciation on the Weddell Sea embayment is simulated in their study, the contribution of the retreat over the Filchner-Ronne area will therefore be closer to the result of the present study.

Huybrechts (2002) presented a reconstruction of the Antarctic ice sheet at the LGM using an ice-sheet model including the effect of changes in grounding line position. He concluded that the Antarctic ice sheet contributed 14$18 \mathrm{~m}$ to the sea-level lowering, which is around $50 \%$ of the result in the present paper. This difference is mainly due to the difference in the grounding line position on the Ross Sea embayment as well as the other marginal areas not connected to the major ice shelves, which have little or no advance of grounding lines. On the other hand, the simulated grounding line position of the Weddell Sea embayment at the LGM of Huybrechts (2002) is similar to the position in the present study.

This difference may be due to the difference in the bedrock topography of the continental shelves. In the Weddell Sea embayment, the horizontal gradient of bedrock topography is very steep at the continental shelf break, such that the -500 and $-1000 \mathrm{~m}$ contours are very close. It is relatively gentle in the Ross Sea embayment, with more distant contours (Bentley, 1999; Lythe and others, 2000). The assumed maximum grounded area in the present study is therefore wider than that shown in Huybrechts (2002) on the Ross Sea embayment.

It is concluded that the influence of climate change on the changes in the ice volume during glacial/interglacial cycles has a minor effect compared to that of the change in the grounded area. The ratio of LGM to present volume of 0.97 , obtained by the transient experiment, indicates that the maximum contribution of the Antarctic ice sheet to global sea-level rise from the LGM to the present is around $36 \mathrm{~m}$.

Since the geometry in the full grounded-area experiments may be regarded as an overestimation of the extent of the grounded ice sheet in the glacial period, the possible volume change may actually be smaller. Moreover, as there would be a delay in achieving the steady state in the response of ice thickness to the position of the ice-sheet margin (which is also transient), the ice-volume change may be even smaller.

The results of the above experiments may be affected by uncertainties in the basal sliding parameterization. Payne (1999) presented a simulation of the West Antarctic ice sheet under the steady present-day climate forcing, with fixed grounding line at the present-day position, using a linear basal sliding parameterization. An increase in the sliding coefficient by a factor of 5 resulted in a $5 \%$ decrease in the simulated ice-sheet volume at the final state (100 ka).

Saito (2002) presented steady-state experiments of the Antarctic ice sheet by fixing the grounding line at the present-day position, with the sliding coefficient multiplied by 0 and 16, respectively, using the same basal-sliding parameterization as in the present paper.

It is found that even if the coefficient is multiplied by a factor of 16 , the change in steady-state ice volume is only $6 \%$, which is comparable to the influence of the enhancement factor differing by a factor of 2 or less. If the uncertainties in the sliding coefficient are smaller by a factor of 10 or less, the sensitivity of the steady-state ice-sheet volume to uncertainties in the basal sliding parameterization is expected to be within the range of results in the present paper using different parameter choices. We conclude that, in the evolution of the Antarctic ice sheet, changes in the grounded area are dominant while those in the climate are minor, as is also stated by Ritz and others (2001) and Huybrechts and others (2002).

The results may also be affected by the uncertainties in the basal sliding if the grounding line position is allowed to advance or retreat under a transient glacial/interglacial forcing. Ritz and others (2001) presented sensitivity experiments designed to investigate the effects of the sliding law on the results of their transient $423 \mathrm{ka}$ simulation of the Antarctic ice sheet. The glacial/interglacial difference in the simulated ice-sheet volume varies by a factor of 1.7 in their results, accompanied by an insufficient retreat of the grounding line to its present-day position in one of their experiments. It will therefore be necessary to investigate the sensitivity of changes in the simulated ice-sheet volume to the uncertainties in the basal sliding parameterization when the grounded area varies under transient climate. This is, however, beyond the scope of the present paper.

A comparison of the contribution of the Antarctic ice sheet to sea-level rise between the (perhaps overestimated) maximum value in the present paper and values found in the 
literature, summarized in Philippon and others (2006), shows that almost all the results of previous studies are within the range of our values with the exception of two studies. Nakada and Lambeck (1988) and Budd and Smith (1982) found 37 and $38 \mathrm{~m}$, respectively, for the contribution of the Antarctic ice sheet to sea-level change. These values are close to the upper limit found in the present study and would only be possible under the most extreme conditions.

Since the grounded area is a dominant factor for the reconstruction of the ice-sheet topography at the LGM, the position of the chosen grounding line is crucial for model reconstructions. Bentley (1999) presented a grounding line position (interpolated and not well constrained) over the Weddell Sea embayment, which is shifted inland by around $200 \mathrm{~km}$ compared to the assumption of the present paper. Using such a configuration on the Weddell Sea embayment, the possible contribution of the Filchner-Ronne Ice Shelf grounding is much reduced. The reconstructed grounded area over the western side of the Antarctic Peninsula (Bentley, 1999) is also smaller than the assumed present configuration in this paper. The effect of the advance in the margin over the regions not connected to the major ice shelves is therefore also reduced under such a configuration.

Similar experiments with intermediate configurations between the extreme LGM case of the present paper and the present-day ice sheet are required. Better constraints on the LGM ice-sheet margin positions (e.g. from geological data) will help to obtain more accurate estimations of the contribution of the major ice shelves and other parts of the ice sheet to the postglacial sea-level change. Moreover, if better information on changes in the surface elevation at several sites based on ice cores can be obtained, the changes in the grounded areas of the major ice shelves and the other parts of the ice sheet may be constrained more reliably. For example, the effect of the Ross region has a dominant effect on the elevation at Vostok, while it is negligibly small on the elevation of Dome Concordia and Dome Fuji. Advances in other ice-shelf margins have a dominant effect on the elevation at Dome Concordia.

There is a debate over whether the source of MWP1a is the Antarctic or the Northern Hemisphere ice sheets. If the global sea-level rise by $20 \mathrm{~m}$ at MWP1a is only due to the Antarctic ice sheet, the present paper shows that the grounding area of a single ice shelf cannot explain the total amount. The grounded-area experiments of the present paper suggest that, for example, about half of the $20 \mathrm{~m}$ could be explained by a single ice shelf and that the other parts of the periphery of Antarctica could add almost enough. It is therefore important to investigate the changes of all grounded areas around the entire Antarctic ice sheet.

\section{CONCLUSIONS}

In the present study, a 3-D thermodynamic ice-sheet model in the shallow-ice approximation is applied to discuss the sensitivity of changes in the ice-sheet volume to glacial/interglacial changes. Steady-state experiments on the area of grounded ice (position of the ice-sheet margin) as well as a transient experiment forced by glacial/interglacial climate changes are performed and discussed.

The maximum possible contribution of the Antarctic ice sheet to sea-level change during the last deglaciation estimated in the present study covers most of the values estimated in previous studies using various methods, with a couple of exceptions. The maximum possible contribution of the Antarctic ice sheet to global sea-level rise, from the LGM to the present, estimated in this study is about $36 \mathrm{~m}$.

The effect of the grounded area on ice volume is shown to dominate the contribution of the transient changes. The effects of grounding of major ice shelves are also separated, and the Filchner-Ronne region is found to have the most significant influence on the change in the ice volume. The maximum possible contribution of the Filchner-Ronne Ice Shelf grounding is around $13 \mathrm{~m}$, one-third of the total change. The sum of contributions from the Ross and Amery regions is also around one-third of the total change. The remaining third is contributed by the advance in the ice-sheet margin over the other regions around Antarctica.

All of the results obtained by the grounded-area experiment in the present paper were obtained using a steady-state experiment. If the timescale of the response of the interior regions to changes in the margin positions is taken into account, the effects of the grounding area decrease.

\section{ACKNOWLEDGEMENTS}

We greatly appreciate the valuable suggestions of two anonymous referees and the scientific editor E. Bueler, which helped to improve the manuscript substantially. We also thank $\mathrm{H}$. Blatter for providing valuable comments on the manuscript. This work was supported by KAKENHI 21740349.

\section{REFERENCES}

Abe-Ouchi, A., T. Segawa and F. Saito. 2007. Climatic conditions for modelling the Northern Hemisphere ice sheets throughout the ice age cycle. Climate Past, 3(3), 423-438.

Ackert, R.P., Jr and 6 others. 1999. Measurements of past ice sheet elevations in interior West Antarctica. Science, 286(5438), 276-280.

Allison, I., R.G. Barry and B. Goodison, eds. 2001. Climate and Cryosphere (CLiC) Project. Science and Co-ordination Plan, Version 1. Geneva, World Meteorological Organization. World Climate Research Programme. (WCRP-114, WMO/TD 1053.)

Bard, E. and 6 others. 1996. Deglacial sea-level record from Tahiti corals and the timing of global meltwater discharge. Nature, 382(6588), 241-244.

Bassett, S.E., G.A. Milne, J.X. Mitrovica and P.U. Clark. 2005. Ice sheet and solid earth influences on far-field sea-level histories. Science, 309(5736), 925-928.

Bassett, S.E., G.A. Milne, M.J. Bentley and P. Huybrechts. 2007. Modelling Antarctic sea-level data to explore the possibility of a dominant Antarctic contribution to meltwater pulse IA. Quat. Sci. Rev., 26(17-18), 2113-2127.

Bentley, M.J. 1999. Volume of Antarctic ice at the Last Glacial Maximum, and its impact on global sea level change. Quat. Sci. Rev., 18(14), 1569-1595.

Bentley, M.J. and J.B. Anderson. 1998. Glacial and marine geological evidence for the ice sheet configuration in the Weddell Sea-Antarctic Peninsula region during the Last Glacial Maximum. Antarct. Sci., 10(3), 309-325.

Budd, W.F. and I.N. Smith. 1982. Large-scale numerical modelling of the Antarctic ice sheet. Ann. Glaciol., 3, 42-49.

Bueler, E. and J. Brown. 2009. Shallow shelf approximation as a 'sliding law' in a thermomechanically coupled ice sheet model. J. Geophys. Res., 114(F3), F03008. (10.1029/2008JF001179.)

Conway, H., B.L. Hall, G.H. Denton, A.M. Gades and E.D. Waddington. 1999. Past and future grounding-line retreat of the West Antarctic ice sheet. Science, 286(5438), 280-283. 
Denton, G.H. and T.J. Hughes. 2002. Reconstructing the Antarctic ice sheet at the Last Glacial Maximum. Quat. Sci. Rev., 21(1-3), 193-202.

Fairbanks, R.G. 1989. A 17,000-year glacio-eustatic sea level record: influence of glacial melting rates on the Younger Dryas event and deep-ocean circulation. Nature, 342(6250), 637-642.

Fortuin, J.P.F. and J. Oerlemans. 1990. Parameterization of the annual surface temperature and mass balance of Antarctica. Ann. Glaciol., 14, 78-84.

Grootes, P.M. and M. Stuiver. 1986. Ross Ice Shelf oxygen isotopes and West Antarctic climate history. Quat. Res., 26(1), 49-67.

Hutter, K. 1983. Theoretical glaciology; material science of ice and the mechanics of glaciers and ice sheets. Dordrecht, D. Reidel Publishing.

Huybrechts, P. 1992. The Antarctic ice sheet and environmental change: a three-dimensional modelling study. Ber. Polarforsch. 99.

Huybrechts, P. 1997. Report of the third EISMINT workshop on model intercomparison. Strasbourg, European Science Foundation.

Huybrechts, P. 2002. Sea-level changes at the LGM from icedynamic reconstructions of the Greenland and Antarctic ice sheets during the glacial cycles. Quat. Sci. Rev., 21(1-3), 203-231.

Huybrechts, P. and J. Oerlemans. 1990. Response of the Antarctic ice sheet to future greenhouse warming. Climate Dyn., 5(2), 93-102.

Huybrechts, P., D. Steinhage, F. Wilhelms and J. Bamber. 2000. Balance velocities and measured properties of the Antarctic ice sheet from a new compilation of gridded data for modelling. Ann. Glaciol., 30, 52-60.

Huybrechts, P., I. Janssens, C. Poncin and T. Fichefet. 2002. The response of the Greenland ice sheet to climate changes in the 21 st century by interactive coupling of an AOGCM with a thermomechanical ice-sheet model. Ann. Glaciol., 35, 409-415.

Huybrechts, P., J. Gregory, I. Janssens and M. Wild. 2004. Modelling Antarctic and Greenland volume changes during the 20th and 21 st centuries forced by GCM time slice integrations. Global Planet. Change, 42(1-4), 83-105.

Imbrie, J. and 8 others. 1984. The orbital theory of Pleistocene climate: support from a revised chronology of the marine $\delta^{18} \mathrm{O}$ record. In Berger, A., J. Imbrie, J. Hays, G. Kukla and B. Saltzman, eds. Milankovitch and climate: understanding the response to astronomical forcing. Part 1. Dordrecht, etc., D. Reidel Publishing, 269-305. (NATO ASI Series C: Mathematical and Physical Sciences 126.)

Lythe, M.B., D.G. Vaughan and BEDMAP consortium. 2000. BEDMAP - bed topography of the Antarctic. (Scale 1:10,000,000.) Cambridge, British Antarctic Survey. (Map no. BAS (Misc) 9.)

Mclntyre, A. and CLIMAP Project members. 1981. Seasonal reconstructions of the Earth's surface at the last Glacial Maximum. Boulder, CO, Geological Society of America. (Map and Chart Series MC-36.)

McKay, R.M., G.B. Dunbar, T.R. Naish, P.J. Barrett, L. Carter and M. Harper. 2008. Retreat history of the Ross Ice Sheet (Shelf) since the Last Glacial Maximum from deep-basin sediment cores around Ross Island. Palaeogeogr., Palaeoclimatol., Palaeoecol., 260(1-2), 245-261.

Nakada, M. and K. Lambeck. 1988. The melting history of the late Pleistocene Antarctic ice sheet. Nature, 333(6168), 36-40.

Oerlemans, J. 1982. A model of the Antarctic ice sheet. Nature, 297(5867), 550-553.

Paterson, W.S.B. 1994. The physics of glaciers. Third edition. Oxford, etc., Elsevier.

Pattyn, F. and H. Decleir. 1995. Numerical simulation of Shirase Glacier, East Queen Maud Land, Antarctica. Proc. NIPR Symp. Polar Meterol. Glaciol., 9, 87-109.

Payne, A.J. 1999. A thermomechanical model of ice flow in West Antarctica. Climate Dyn., 15(2), 115-125.

Peltier, W.R. 2002. On eustatic sea level history: Last Glacial Maximum to Holocene. Quat. Sci. Rev., 21(1-3), 377-396.

Petit, J.R. and 18 others. 1999. Climate and atmospheric history of the past 420,000 years from the Vostok ice core, Antarctica. Nature, 399(6735), 429-436.

Philippon, G., G. Ramstein, S. Charbit, M. Kageyama, C. Ritz and C. Dumas. 2006. Evolution of the Antarctic ice sheet throughout the last deglaciation: a study with a new coupled climate/north and south hemisphere ice sheet model. Earth Planet. Sci. Lett., 248(3-4), 750-758.

Pollard, D. and R.M. DeConto. 2009. Modelling West Antarctic ice sheet growth and collapse through the past five million years. Nature, 458(7236), 329-332.

Ritz, C., V. Rommelaere and C. Dumas. 2001. Modeling the evolution of Antarctic ice sheet over the last 420,000 years: implications for altitude changes in the Vostok region. J. Geophys. Res., 106(D23), 31,943-31,964.

Saito, F. 2002. Development of a three dimensional ice sheet model for numerical studies of Antarctic and Greenland ice sheet. Tokyo, University of Tokyo. Center for Climate System Research. (CCSR Rep. 15.)

Saito, F. and A. Abe-Ouchi. 2004. Thermal structure of Dome Fuji and east Dronning Maud Land, Antarctica, simulated by a three-dimensional ice-sheet model. Ann. Glaciol., 39, 433-438.

Satow, K., O. Watanabe, H. Shoji and H. Motoyama. 1999. The relationship among accumulation rate, stable isotope ratio and surface temperature on the plateau of east Dronning Maud Land, Antarctica. Polar Meteorol. Glaciol., 13, 43-52.

Schoof, C. 2007. Ice sheet grounding line dynamics: steady states, stability, and hysteresis. J. Geophys. Res., 112(F3), F03S28. (10.1029/2006JF000664.)

Vieli, A. and A.J. Payne. 2005. Assessing the ability of numerical ice sheet models to simulate grounding line migration. J. Geophys. Res., 110(F1), F01003. (10.1029/2004JF000202.)

Weertman, J. 1964. The theory of glacier sliding. J. Glaciol., 5(39), 287-303.

Yokoyama, Y., P. de Deckker, K. Lambeck, P. Johnston and L.K. Fifield. 2001. Sea-level at the Last Glacial Maximum: evidence from northwestern Australia to constrain ice volumes for oxygen isotope stage 2. Palaeogeogr., Palaeoclimatol., Palaeoecol., 165(3-4), 281-297. 